\title{
Understanding the Intention to Use Virtual Currency in a Gamified E-Commerce Context
}

\author{
Anoop George, Cochin University of Science and Technology, India \\ Manu Melwin Joy, Cochin University of Science and Technology, India \\ Muhammed Sajid, Cochin University of Science and Technology, India \\ Muhammed Nowfal S., Cochin University of Science and Technology, India
}

\begin{abstract}
Gamification is all about using game features in a serious context to encourage people to use products or services. E-commerce has used gamification for marketing determinations to strengthen intent to use. Technology acceptance model is employed in the current study to investigate the intention to use gamified virtual currency in the Indian context. A survey was used to accumulate records from a random sample of relevant virtual currency users in an e-commerce context using a quantitative approach. Structural equation modeling (SEM) is expended for data analysis in this research. This empirical research shows the incremental impact of the users' perceptions of the ease of use and usefulness on intention to use virtual currency. The variable attitude seems to be not mediating significantly. There are also discussions, restrictions, and future research directions mentioned in this study.
\end{abstract}

\section{KEYWORDS}

E-Commerce, Gamification, TAM, Usage Intention, Virtual Currency

\section{INTRODUCTION}

Is there anyone who never played anything in their childhood? Hide and seek, tag, musical chair, pen - paper - scissors, so on, to name a few. Do you think playing remains only for childhood days? Cricket, football, field hockey, etc., to name a few. Playing games have always been a cross-generational activity that piqued interest and fun (Huotari \& Hamari, 2017). More than a billion people play games on mobile globally (Joensuu \& Ryynänen, 2019). No doubt that the game makes the play more fun and entertaining (Heeter et al., 2011). And many are part of serious games knowingly or unknowingly, which can be considered as something beyond fun and entertainment. Like the concept of serious games, gamification uses game elements but as part of an entertainment game for purposes other than their regular expected use (Buckley et al., 2019). Gamification has been more specifically welldefined as "the use of game design elements in non-game contexts" (Deterding, 2012). Gamification in this context can be defined by employing or embedding the features of game elements like virtual currency, leader boards, points, etc., as a set of any specific behavior and processes applied for getting better engagement of its consumers (Bozkurt \& Durak, 2018). Gamification is an efficient design strategy that is still developing in recent years for driving game mechanics into existing real-life 
contexts, especially in e-commerce (Rapp et al., 2019). The interest in gamification in academics and e-commerce is increasing, and it has already been proven. Still, the absence of enough empirical evidence on individual game elements, especially in online commerce(García-Jurado et al., 2019), is something important that needs to be studied. India, being one among the internationally recognized, quick developing, and most significant emerging e-commerce industries that expect to cross 200 billion US dollars by 2026 from 38.5 billion US dollars as of 2017 (E-Commerce in Indial IBEF, 2021).

Flipkart, along with other minor specialist e-commerce platforms, is presently among the most dominant e-tailers in the Indian e-commerce industry (Prashar et al., 2015; Rajan, 2020). Flipkart Plus is a no-cost successful loyalty initiative for all of its regular customers (Trauboth, 2020). Buyers must earn five hundred SuperCoins to be eligible for this program. Flipkart Plus members earn four SuperCoins per each one hundred rupees invested on a Flipkart purchase, while non-plus customers receive two SuperCoins (Gayathry, 2019). Flipkart SuperCoins is one of the limited virtual currencies used for e-tailing (Moin \& Rahman, 2019). The virtual currency reward system that has got some exchange value within the system can be considered virtual currency in the gamification framework (Dicheva et al., 2021). Therefore the virtual currency has got an attribute of private currency that is mainly used in online transactions by using various technological factors. In the case of Flipkart SuperCoins, it can be used for payment for the products, buying coupons, buy exclusive deals and book flight tickets by using the same platform (Flipkart, 2019). The fact of the matter is that virtual currency is slowly replacing real physical currency in the e-commerce context, but nobody is having enough statistical proof on the exact replacement. If we consider the Indian population, there is a tremendous amount of interest invested in virtual currencies (Mohammad Usman, 2020). According to the recent statistics, India being appraised to contribute around ten percent of the overall virtual currency market worldwide. Even though more than one thousand five hundred types of virtual currencies are seen in India (Sackheim \& Howell, 2018), we could hardly find the virtual currency in an e-commerce platform. This scenario constantly questions how far the virtual currency is affecting real-life scenarios (Wang \& Mainwaring, 2008). This question remains in the mind of both academicians and business people. Therefore this investigation focuses on virtual currency in a gamified e-commerce context. The gamified virtual currency considered for this empirical study is SuperCoins which are stored and transacted only through the Flipkart domain's designated mobile application or website.

The use of game elements like virtual currency and its game mechanics and game dynamics in non-game situations like e-commerce has become one of the fastest emerging practices in marketingrelated activities (Yang et al., 2017). Whatsoever the research that provides empirical studies as evidence for game elements' influence on consumer behavior in domains like e-commerce marketing is still deficient (Behl et al., 2020; Deterding et al., 2011). From the existing pieces of literature, it is clearly understood that virtual currency is a gamification element (Helmefalk et al., 2019), and there is a need to identify the relevance of virtual currency concerning consumer behavior perspective in an e-commerce context (Kamboj et al., 2020). There is a clear requirement of empirical research that would examine how each single gamification element like virtual currency individually affect the business environment (Azmi et al., 2021; Xi \& Hamari, 2020). Therefore, this study comprises empirical research to bridge the gap on how far this individual game element called virtual currency is affecting the individual's intention to use SuperCoins in the environment of e-business by using the Technology Acceptance Model (TAM).

The key research questions are as follows:

- Determining whether and how much a specific game mechanic termed virtual currency influences e-commerce usage intention?

- To forecast customer behavior in virtual e-commerce environments, should 'Attitude' be used in conjunction with the existing TAM framework, which is in conflict? 


\section{LITERATURE REVIEW}

\section{The SuperCoins of Flipkart - Virtual Currency}

Whether it's their business practices, product catalogs, web designs, or service offers like rewards, the e-commerce platform should learn what matters effectively for them (Khanna \& Sampat, 2015). Flipkart, an e-commerce platform, employs gamification rewards as a promotional and engagement technique to entice more people to visit their platforms on a continuous basis for their success (Raj \& Gupta, 2018). "Use of immediate signs of accomplishment through virtual and monetary rewards" is how rewards are defined (Conaway \& Garay, 2014). Virtual currency is a kind of reward that is used in gamified context. Virtual currency is something that works like money (Kňažková \& Ondrušová, 2019) but definitely, nothing to do with real cash in gamified framework. Virtual currency's existence in a gamified system leads to the formation of a virtual economy. Customers can receive virtual currency called SuperCoins as a reward from Flipkart, and they can also use the same virtual currency as a payment option (Moin \& Rahman, 2019). Therefore Flipkart SuperCoins somewhat act as a medium of exchange or function like a currency, and such kind exchange of virtual currency can also be seen in many online gaming websites (Shin, 2008). The main focus of the virtual currency used by Flipkart called SuperCoins is to bring customer loyalty. This supposition is based on the sense that the virtual currency can be used for redeeming tangible goods will be good enough to motivate customers to come back and enhance the buying behavior. But the lack of empirical evidence on the above-stated logic leads this research.

\section{Technology Acceptance Model (TAM)}

Theory of Reasoned Action (TRA) (Fishbein \& Ajzen, 1975) is the basic inspiration for the formation of the Technology Acceptance Model (TAM) and is used to envisage the acceptance of technology. The Technology Acceptance Model is a widely used model for studying online consumer behavior, especially in e-commerce shopping (Aparicio et al., 2021; Aydin, 2015). One of the worldwide accepted models is Technology Acceptance Model (TAM), especially in an online shopping context in order to predict any kind of adoption of new technologies like Gamification (Raman, 2020). Past studies that used the Technology Acceptance Model have observed the value of Cronbach'sreliability more than 0.9 and considered scales of the Technology Acceptance Model that have got a greater level of convergent validity, discriminant validity, and construct validity(Davis \& Venkatesh, 1996). Therefore this study is conducted with an underlying theoretical framework called Technology Acceptance Model (TAM). The two independent variables, perceived usefulness and perceived ease of use, are explored in this research that influences the dependant variable intention to use in the framework of the virtual currency called SuperCoins through user survey research with the help of a mediating variable called attitude.

\section{Perceived Usefulness (PU)}

According to (Davis, 1989)the variable perceived usefulness is described by way of "the degree to which an individual believes that using a particular system will improve his or her job performance." The description refers to whether or not anyone considers a piece of technology to be helpful for the task at hand. According to (Lin, 2007), if we consider the virtual community's environment, perceived usefulness specifies the users' confidence in their ability to achieve information and amenities, share their know-how with other people around, and augment their performance in information interchange while using the virtual community. Perceived usefulness is considered an important factor in innovative technology adoption (Kim et al., 2017). The significance and usefulness of technology is still a concern for organisations due to a rise in solutions and technological advancements (McLean \& Wilson, 2016). Therefore this study considers perceived usefulness, the one for which a user believes in the existence of a positive attitude-intention relationship. 
H1: Perceived usefulness has a positive influence on attitude toward employing the virtual currency. H2: Perceived usefulness has a positive influence on the intention to use virtual currency.

\section{Perceived Ease of Use (PEOU)}

According to (Davis, 1989) perceived ease of use is well-defined as "the degree to which a person believes that using a particular system would be free of effort." The word ease can be further explained as the freedom from strain or great energy. In this research, the exact definition of perceived ease of use for framing the hypothesis. The study by (R. Hendrickson \& R. Collins, 1996)confirmed that there is an existence of a straight connection between perceived ease of use and intention to use.The Technology Acceptance Model's empirical studies have clearly demonstrated that perceived ease of use has a major positive impact on attitude and intention (Khan, 2021; Wong et al., 2021). The gamification scenario, especially in the Indian E-commerce context, is still considered an innovation. Initial acceptance of an invention is aided by the variable perceived ease of use, which is essential for favorable reception and sustained use(Davis et al., 1989). All these contexts are considered for this study.

H3: Perceived ease of use has a positive influence on attitude toward using virtual currency.

H4: Perceived ease of use has a positive influence on the intention to use virtual currency.

\section{Attitude (AT) and Intention to Use (IU)}

In the context of this study, the mediating variable attitude is well-defined as "the extent to which a person's positively or negatively evaluate or assess the behavior." The key component and direct antecedent of doing a specific behavior, per the TRA, is "intention" (Aydin, 2015). Both the variables are considered for predicting the intention to use SuperCoins. Initially, research on Technology Acceptance Model (TAM) clearly claims that the attitude on the way to action has an affirmative influence on users' intention, leading to people performing an action. The attitude was eventually eliminated from the Technology Acceptance Model (TAM) as it was shown that it was not directly associated with the use of technology (Teo, 2009). Further studies on Technology Acceptance Model (TAM) also say that the mediating variable attitude may or may not have an impact on a person's intention toward using technology and, it still remains a point of discrepancy among researchers (López-Bonilla \& López-Bonilla, 2017). There are also studies using Technology Acceptance Model (TAM) without applying the mediator attitude (R. Hendrickson \& R. Collins, 1996). Whatsoever this study is also trying to figure out the relevance of mediation because most of the studies conducted in TAM has got the tremendous contextual difference (Azmi et al., 2021). The validity of the Technology Acceptance Model (TAM) model used in the research is also confirmed through the following hypotheses.

H5: Attitude toward virtual currency has an affirmative influence on the intention to use virtual currency.

\section{METHODOLOGY}

\section{Data Collection and Sample}

The primary goal of this research is to understand the intention to use virtual currency in an e-commerce platform called Flipkart. An internet-based questionnaire survey was used and administered for this research from January 2021 to February 2021. Even though we got the responses from 210 participants, we have screened and taken only responses of 165 participants who are Indian nationals relevant for the 


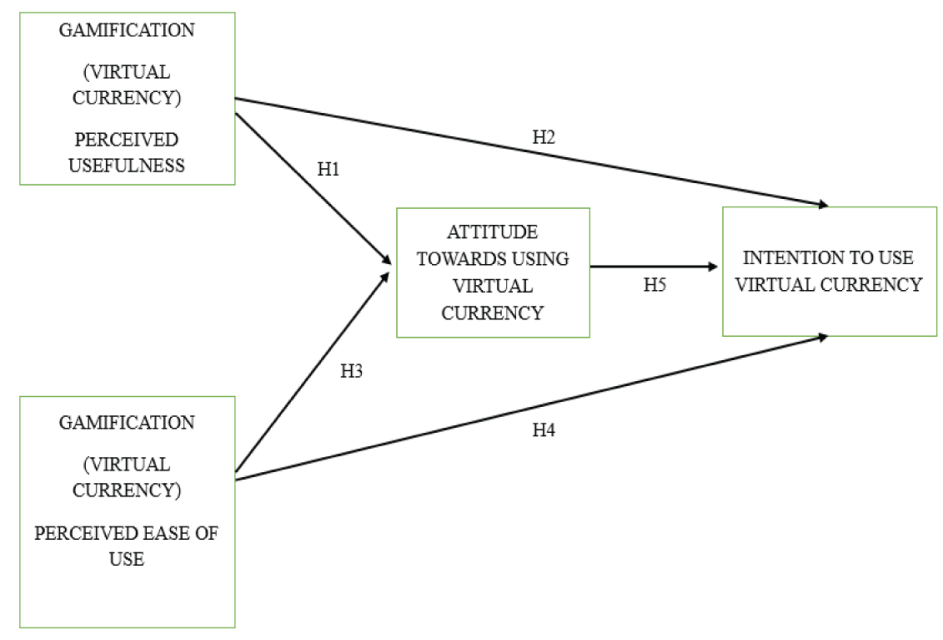

study, and therefore, the sample size for this research is $\mathrm{N}=165$. Even now, in e-commerce websites in India, the embedding of virtual currencies is not yet commonplace.; therefore, it was quite necessary to toe the line that the respondents had enough understanding about the virtual currency. Hence, we screened each and every response to determining whether or not users had considerable awareness of this manner of interchange. Considering the respondents' data, most of the participants in the study fall in the age category of 21-30 years and 31-40 years, representing 73\% of the total sample. The distribution of the gender-wise data of the selected sample shows that $60 \%$ of the participants were males, and $40 \%$ of the participants were females. Most of the participants were professionals contributing to $42 \%$, followed by students $25 \%$. About $67 \%$ of the respondents have been using Flipkart for more than three years.

\section{Measurement}

An online questionnaire survey was conducted to gather the data. The instrument for data collection was developed grounded on the relevant evaluation of pieces of literature and was used to measure each construct. The instrument for the research had 13 items basically representing four different variables as mentioned in the model of the research, and its sources are publicized in the Appendix. The questionnaire was done by means of the 7-point Likert- scale type, which ranges from "strongly disagree" to "strongly agree," and all these were drawn from previously validated instruments. The variable perceived usefulness was finally assessed through 3 items taken from (Davis, 1989), which assessed the magnitude to which a person believes that virtual currency could be used favorably with provided positive, predictable results. The variable perceived ease of use was finally assessed with three items scale taken from (Venkatesh, 2000). The mediating variable called attitude is measured by using three items scale taken from (Van Der Heijden, 2004). The intention to use was the dependent variable that the researcher used, and it was measured by using four items scaled adopted from (Davis, 1989).

\section{Data Analysis}

The measuring instruments' reliability and validity had been checked with Partial Least Squares (PLS), and the test was also done using WarpPLS. There are more than a few reasons for using the Partial Least Squares (PLS) regression method. (Reinartz et al., 2009) had already claimed that Partial Least Square is beneficial for a lot of multi-dimensional models of a predictive nature with sample sizes that were comparatively lower, and for this study, the sample size (N) was 165 , which matches 
the relatively small size. Therefore the researcher identified that Partial Least Squares (PLS) was the better statistical approach considering the circumstances of this research. Convergent validity, discriminant validity, and tests for reliability were directed grounded on methods commonly used for empirical studies. Initially, the quality of being dependent on the survey questionnaire was checked by calculating Cronbach's $\alpha$ to establish internal consistency. Every single item's reliability was inspected using composite factor analysis. The results obtained from both the analysis satisfy the condition that all of the findings were upper than the suggested standard of 0.7. Each item's outcomes are mentioned in table 1, and the further breakup of each construct is detailed in Table 2.

Table 1. Reliability analysis

\begin{tabular}{|l|l|l|}
\hline \multicolumn{1}{|c|}{ Constructs } & \multicolumn{1}{c|}{ Cronbach's $\boldsymbol{\alpha}$} & \multicolumn{1}{c|}{ Composite Factor Reliability } \\
\hline Perceived Usefulness & 0.945 & 0.946 \\
\hline Perceived Ease of Use & 0.938 & 0.942 \\
\hline Attitude & 0.936 & 0.941 \\
\hline Intention to Use & 0.955 & 0.955 \\
\hline
\end{tabular}

Table 2. The constructs reliability values

\begin{tabular}{|l|l|l|l|l|l|l|}
\hline \multicolumn{1}{|c|}{ Constructs } & $\begin{array}{c}\text { Items in the } \\
\text { beginning }\end{array}$ & $\begin{array}{c}\text { Final } \\
\text { items }\end{array}$ & Variables & M (SD) & Standard error & $\begin{array}{c}\text { Composite factor } \\
\text { reliability }\end{array}$ \\
\hline $\begin{array}{l}\text { Perceived } \\
\text { Usefulness }\end{array}$ & 5 & 3 & PU1 & $5.129(1.625)$ & 0.083 & 0.946 \\
\hline & & & PU2 & & 0.063 & \\
\hline & & & PU3 & & 0.057 & \\
\hline $\begin{array}{l}\text { Perceived Ease } \\
\text { of Use }\end{array}$ & 3 & 3 & PEOU1 & $4.721(1.680)$ & 0.067 & 0.942 \\
\hline & & & PEOU2 & & 0.067 & \\
\hline & & & PEOU3 & & 0.102 & \\
\hline Attitude & 4 & 3 & AT1 & $5.484(1.385)$ & 0.08 & 0.941 \\
\hline & & & AT2 & & 0.04 & \\
\hline & & & AT3 & & 0.045 & \\
\hline Intention to Use & 4 & 4 & IU1 & $5.172(1.634)$ & 0.106 & 0.955 \\
\hline & & & IU2 & & 0.058 & \\
\hline & & & IU3 & & 0.057 & \\
\hline & & & IU4 & & 0.051 & \\
\hline
\end{tabular}

The method that we employed to check the model's convergent and discriminant validity was suggested by (Fornell \& Larcker, 1981). The same procedure was used in this study as well. The item loadings, cross-loadings, and average variance derived in this study were examined carefully and methodically by using exploratory factor analysis (AVE) and also conducted a convergent validity test to confirm consistency across items. Through the test, it was identified that the loadings of each item surpassed the smallest detectable sensation of 0.7 (Chin et al., 2003) and hence indicated 
convergent validity. The shared variance between constructs has been compared with the average variance extracted (AVE) from the individual constructs for examining the discriminant validity of this study. The average variance extracted (AVE) from the individual constructs was less than the shared variance between constructs, confirming the discriminant validity of the constructs used in the research. The inter-construct correlation referring to the construct's diagonal correlations to their latent variables is smaller than the square root of average variance derived (AVE) for all constructs(Loch et al., 2003). Therefore, it proves discriminant validity. In table 3, the specifics of both convergent and discriminant validity are described.

Table 3. Discriminant validity and Convergent validity

\begin{tabular}{|l|c|c|c|c|c|c|c|c|}
\hline \multicolumn{1}{|c|}{ Constructs } & CR & AVE & MSV & \multicolumn{1}{c|}{ MaxR(H) } & \multicolumn{1}{c|}{$\mathbf{4}$} & $\mathbf{3}$ & $\mathbf{2}$ & $\mathbf{1}$ \\
\hline Intention to Use & 0.955 & 0.841 & 0.719 & 0.962 & $\mathbf{0 . 9 1 7}$ & & & \\
\hline Attitude & 0.941 & 0.841 & 0.601 & 0.952 & 0.727 & $\mathbf{0 . 9 1 7}$ & & \\
\hline Perceived Usefulness & 0.946 & 0.853 & 0.719 & 0.952 & 0.848 & 0.776 & $\mathbf{0 . 9 2 3}$ & \\
\hline Perceived Ease of Use & 0.942 & 0.844 & 0.707 & 0.948 & 0.841 & 0.733 & 0.781 & $\mathbf{0 . 9 1 9}$ \\
\hline
\end{tabular}

\section{RESULTS}

The complete model fit had been checked along with the quality indices. The average path coefficient (APC) value is 0.354 , the average $\mathrm{R}$-squared (ARS) value is 0.684 , and the average adjusted $\mathrm{R}$-squared (AARS) value is 0.679 ; all the values are shown significance $(\mathrm{P}<0.001)$. The average block VIF (AVIF) is 2.593, and the acceptable if value is ideally less than or equal to 3.3. According to (Kock, 2011) the standards for both average path coefficient (APC) and average R-squared ought to be below 2 ( 0.05 level significance), whereas the AVIF value ought to be lesser than 5 . The average full collinearity VIF (AFVIF) $=3.376$, and it is acceptable since the value is less than or equal to 5 . The models TenenhausGoF (GoF) is 0.781 . The Simpson's paradox ratio (SPR) is 1.000 , which ideally should be equal to 1 . The R-squared contribution ratio (RSCR) is 1.000 , which ideally should be equal to 1 . The statistical suppression ratio (SSR) is 1.000 , which is acceptable if the value is greater than or equal to 0.7 . The nonlinear bivariate causality direction ratio (NLBCDR) is 1.000 , which is acceptable if the value is greater than or equal to 0.7 . The researchers identified the structural equation framework has a good fitness for the data from the above values. The average total collinearity value also infers low overall collinearity, as a result representing trivial method variance.

In order to support the hypothesis, the beta coefficient $(\beta)$ of affiliation essential be at 0.05 for the significance otherwise underneath the mentioned value (Sarstedt et al., 2014). The adjusted R squared value for each hypothesis is also checked, which specifies the independent variables' explanatory influence on the dependent variable. The respective values are detailed in table 4 . As indicated in table 4, the perceived usefulness and ease of use on the importance of virtual currency usage intention shows a significant positive relationship with the dependent variable attitude and describes $61.8 \%$ of the variance in attitude. Therefore it supports hypotheses 1 and 3. The independent variables such as perceived usefulness and perceived ease of use, along with the non-significant mediating variable, explain $74.1 \%$ of the change in the dependent variable intention to use, thereby supporting hypothesis 2 and hypothesis 4 . TAM models are used widely in two different ways: TAM with attitude (TAM-O) and TAM without the attitude (TAM-R). As a result, none of them seems to have the upper hand. There have been studies that show that adjusting one's attitude toward technical usage is insufficient to hold this definition in TAM (López-Bonilla \& López-Bonilla, 2017). Whatsoever scenario plays a critical role in deciding the need for the TAM mediation variable for the research. In our indirect 
study effect of attitude towards intention to use is not significant. Considering the factors like this study happens in gamified virtual currency scenario, and the research happens in the Indian context, the direct relationship plays more importance than the indirect relationship. Future researches on this discrepancy can help to realize a better understanding of this subject.

Figure 2. The tested structural framework of intention to use virtual currency

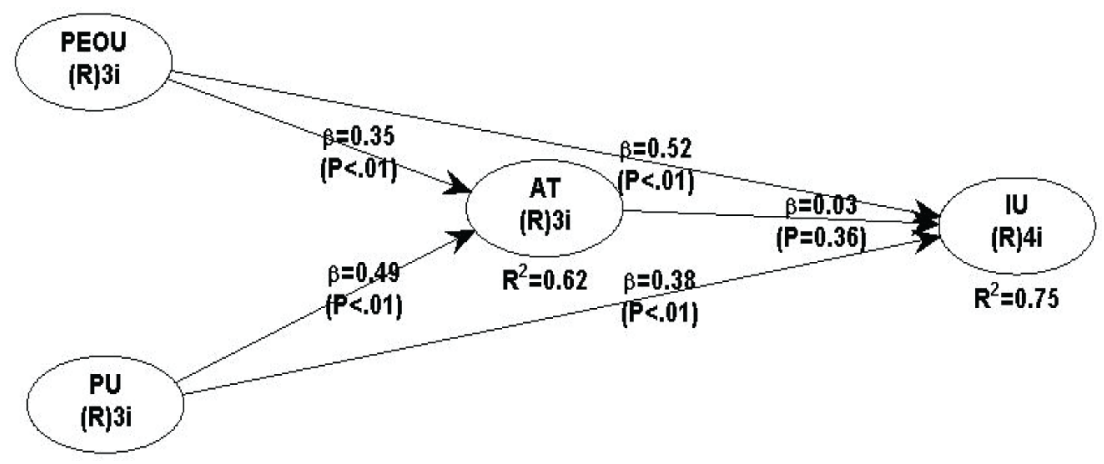

Table 4. PLS-SEM results of the full model

\begin{tabular}{|l|l|l|l|l|}
\hline \multicolumn{1}{|c|}{ Path } & \multicolumn{1}{c|}{ Hypothesis } & \multicolumn{1}{c|}{ Path coefficient $(\boldsymbol{\beta})$} & \multicolumn{1}{c|}{ Adjusted R2 } & \multicolumn{1}{c|}{ Significance } \\
\hline $\mathrm{PU} \rightarrow \mathrm{AT}$ & H1 is supported & 0.49 & 0.618 & $\mathrm{P}<0.01$ \\
\hline $\mathrm{PU} \rightarrow \mathrm{IU}$ & H2 is supported & 0.38 & 0.741 & $\mathrm{P}<0.01$ \\
\hline PEOU $\rightarrow$ AT & H3 is supported & 0.35 & 0.618 & $\mathrm{P}<0.01$ \\
\hline PEOU $\rightarrow \mathrm{IU}$ & H4 is supported & 0.52 & 0.741 & $\mathrm{P}<0.01$ \\
\hline $\mathrm{AT} \rightarrow \mathrm{IU}$ & H5 is not supported & 0.03 & 0.741 & $\mathrm{P}<0.36$ \\
\hline
\end{tabular}

\section{DISCUSSIONS AND CONCLUSION}

\section{Theoretical Implications}

The antecedents and outcomes of the usage of virtual currency in the Indian context were investigated using the Technology Acceptance Model (TAM) (Davis et al., 1989). The purpose of this study was to exam empirically in order to understand the nature of people's behavioral intentions to use virtual currency. The calculation and structural model testing findings back up the proposed research model to a greater extend. Overall, all theories demonstrating direct relationships were confirmed, while indirect relationships were not confirmed significantly, according to the results. There have been prior studies that found no mediation of the variable attitude in TAM (Tobbin, 2014), and it is likely that a stronger understanding and forecasting of behavioral intentions can be reached provided attitudes' multifaceted effects are correctly included for mediation. The mediation of attitude in TAM was a subject of discrepancy among the researchers for a long time (López-Bonilla \& López-Bonilla, 2017), and another reason probably be the methodology used in this research may have had an effect on the outcome.

According to the empirical evidence, the independent variable perceived ease of use has a positive direct affinity on the intention to use virtual currency, which matches prior studies (Aydin, 2015). It means that the higher the degree to which an individual relies on that using gamified virtual 
currency would be permitted of struggle, the higher the strength of one's intention to perform a specified behavior of virtual currency usage. Similarly, the independent variable perceived usefulness has a significant positive relationship with virtual currency's intention to use, where the result is in accordance with the outcomes of previous research (Aydin, 2018). This means that the higher the degree to which a person believes that using gamified virtual currency would enhance his or her performance, the higher the strength of one's purpose to carry out a particular action of virtual currency usage. Users, on the other hand, are more likely to adopt a virtual currency because it involves reduced work or provides advantages in their operations. In other terms, if consumers can exert less effort when using a virtual currency like SuperCoins, the level of perceived usefulness or perceived ease of use is improved, and these findings are consistent with earlier studies in a similar setting (Tony et al., 2020).

Theoretical contributions to the topic of gamification are made in this paper. Although prior publications have looked into the topic of gamification aspects being adopted, the matter of individual game mechanics like virtual currency being applied to the e-commerce environment is still up for debate. The research utilized the Technology Acceptance Model to show the effects of perceived ease of use, perceived usefulness, and attitude on behavioral intention, with results that are not completely identical to those of earlier studies. As a result, the external validity of the Technology Acceptance Model must be studied again in the gamification environment, taking individual game mechanics into account.

\section{Practical Implications}

For gamification consultants and designers, this study has various practical consequences. Certain criteria that need to be considered in order to improve the acceptance of gamified virtual currencies are perceived ease of use and perceived usefulness, which are important factors influencing the desire to use virtual money in an e-commerce setting. For gamification designers, gamification consultants, and customer experience programmers, the characteristics of perceived ease of use and perceived usefulness may provide some inspiration for adopting the same in different e-tailing contexts. People are far more likely to adopt gamified virtual currency if it requires less exertion or has capabilities that meet their needs. Gamification designers and developers could provide a set of tutorials or videos to help customers learn how to utilize gamified virtual currency for the first time. As a result, people can see the significance of rewards like virtual currency in e-commerce. Furthermore, the ease of usage of virtual currency may alleviate the difficulties experienced by early users. As a result, the ease of use of such gamification mechanics will be perceived by the early adopters.

\section{Limitations and the Scope for Future Research}

The current investigation has some drawbacks that scholars can discuss in future studies. A non-random sample is used since a randomly selected sample from the study's population is difficult to obtain. As a measure, the PLS-SEM was chosen as the most suitable tool for statistical analysis with regard to this investigation. The research on the same concept with a larger sample size by using different methodology might yield different outcomes. This paper will provide further research opportunities for the already intensely discussed topic of the role of attitude in the technology acceptance model (TAM). Besides, the term gamified virtual currency is not too broad. Additional game features such as scores, badges, and feedbacks may be incorporated into future research to expand the scope of gamification. The analysis was restricted to the Indian background. The virtual currency we chose for the study was SuperCoins, and future research could involve more virtual currencies to extend the findings. Further research can examine the virtual currency's intention to use from both a quantitative and qualitative angle. This can provide a clear blueprint to highlight the association among independent variables such as perceived usefulness, perceived ease of use, and the dependant variable intention to use virtual currency. Current research collected facts from target respondents in India over and done with an online questionnaire survey. As a result, it is suggested that this analysis be carried 
out in a more number developing nation or a proportional investigation between two nations with dissimilar beliefs be used. For further research, a multi-group study based on a social demographic function is also suggested.

\section{Conclusion}

Through examining the effects of a single gaming mechanic known as virtual currency on e-commerce customers, the study addressed a gap in the literature. The purpose of this research was to examine if TAM's theoretical assumptions for undermining the impact of virtual currency on its usage intention could be implemented to the scenario of e-commerce among individual customers. According to the findings, there is a significant positive association between perceived ease of use, perceived usefulness, and customer intent to use the the gamified virtual currency. The non mediation of the variable attitude is notable in contrast to the existing TAM model. With the insights obtained from these structural relationships in this study, future researchers are encouraged to build on the findings of this study. 


\section{REFERENCES}

Aparicio, M., Costa, C. J., \& Moises, R. (2021). Gamification and reputation: Key determinants of e-commerce usage and repurchase intention. Heliyon, 7(3), e06383. doi:10.1016/j.heliyon.2021.e06383 PMID:33748467

Aydin, G. (2015). Adoption of Gamified Systems. International Journal of Online Marketing, 5(3), 18-37. doi:10.4018/IJOM.2015070102

Aydin, G. (2018). Effect of demographics on use intention of gamified systems. International Journal of Technology and Human Interaction, 14(1), 1-21. doi:10.4018/IJTHI.2018010101

Azmi, L. F., Ahmad, N., \& Iahad, N. A. (2021). Gamification Elements in E-commerce -. RE:view, 1-5, 1-5. Advance online publication. doi:10.1109/ICOTEN52080.2021.9493475

Behl, A., Sheorey, P., Pal, A., Veetil, A. K. V., \& Singh, S. R. (2020). Gamification in E- Commerce. Journal of Electronic Commerce in Organizations, 18(2), 1-16. doi:10.4018/JECO.2020040101

Bozkurt, A., \& Durak, G. (2018). A systematic review of gamification research: In pursuit of homo ludens. International Journal of Game-Based Learning, 8(3), 15-33. doi:10.4018/IJGBL.2018070102

Buckley, P., Noonan, S., Geary, C., MacKessy, T., \& Nagle, E. (2019). An empirical study of gamification frameworks. Journal of Organizational and End User Computing, 31(1), 22-38. doi:10.4018/JOEUC.2019010102

Chin, W. W., Marcelin, B. L., \& Newsted, P. R. (2003). A partial least squares latent variable modeling approach for measuring interaction effects: Results from a Monte Carlo simulation study and an electronic-mail emotion/ adoption study. Information Systems Research, 14(2), 189-217. Advance online publication. doi:10.1287/ isre.14.2.189.16018

Conaway, R., \& Garay, M. C. (2014). Gamification and service marketing. SpringerPlus, 3(1), 1-11. doi:10.1186/2193-1801-3-653 PMID:25392812

Davis, F. D. (1989). Perceived usefulness, perceived ease of use, and user acceptance of information technology. MIS Quarterly: Management Information Systems, 13(3), 319-339. doi:10.2307/249008

Davis, F. D., Bagozzi, R. P., \& Warshaw, P. R. (1989). User Acceptance of Computer Technology: A Comparison of Two Theoretical Mode. INFORMS. https://www.jstor.org/stable/2632151

Davis, F. D., \& Venkatesh, V. (1996). A critical assessment of potential measurement biases in the technology acceptance model: Three experiments. International Journal of Human-Computer Studies, 45(1), 19-45. doi:10.1006/ijhc.1996.0040

Deterding, S. (2012). Gamification. Interaction, 19(4), 14-17. doi:10.1145/2212877.2212883

Deterding, S., Dixon, D., Khaled, R., \& Nacke, L. (2011). From Game Design Elements to Gamefulness: Defining "Gamification." Proceedings of the 15th International Academic MindTrek Conference: Envisioning Future Media Environments, MindTrek 2011, 9-15. doi:10.1145/2181037.2181040

Dicheva, D., Hsin, W.-J., Dichev, C., Guy, B., Cassel, L., \& Irwin, K. (2021).. . Exploring the Effect of Virtual Currency on Learners Engagement, 83-87, 83-87. Advance online publication. doi:10.1109/ ICALT52272.2021.00033

E-commerce in India IBEF. (2021). https://www.ibef.org/industry/ecommerce.aspx

Fishbein, M., \& Ajzen, I. (1975). Belief, Attitudes, Intention, and Behavior. An Introduction to Theory and Research. Addison-Wesley.

Flipkart. (2019). SuperCoin Zone. https://www.flipkart.com/supercoin

Fornell, C., \& Larcker, D. F. (1981). Evaluating Structural Equation Models with Unobservable Variables and Measurement Error. JMR, Journal of Marketing Research, 18(1), 39-50. doi:10.1177/002224378101800104

García-Jurado, A., Castro-González, P., Torres-Jiménez, M., \& Leal-Rodríguez, A. L. (2019). Evaluating the role of gamification and flow in e-consumers: Millennials versus generation X. Kybernetes, 48(6), 1278-1300. doi:10.1108/K-07-2018-0350 
Gayathry, S. (2019). Stay home and shop online-The Flipkart story. Infokara Research, 8(11), 458-469. http:// infokara.com/gallery/227-nov-213.pdf

Heeter, C., Lee, Y. H., Magerko, B., \& Medler, B. (2011). Impacts of forced serious game play on vulnerable subgroups. International Journal of Gaming and Computer-Mediated Simulations, 3(3), 34-53. doi:10.4018/ jgcms.2011070103

Helmefalk, M., Lundqvist, S., \& Marcusson, L. (2019). The Role of Mechanics in Gamification. International Journal of Virtual and Augmented Reality, 3(1), 18-41. doi:10.4018/IJVAR.2019010102

Hendrickson, R., \& Collins, M. R. (1996). An Assessment of Structure and Causation of IS Usage. The Data Base for Advances in Information Systems, 27(2), 61-67. doi:10.1145/243350.243361

Huotari, K., \& Hamari, J. (2017). A definition for gamification: Anchoring gamification in the service marketing literature. Electronic Markets, 27(1), 21-31. doi:10.1007/s12525-015-0212-z

Joensuu, K., \& Ryynänen, S. (2019). The Significance of the Hermeneutics of Play for Gamification. International Journal of Innovation in the Digital Economy, 10(3), 13-23. doi:10.4018/IJIDE.2019070102

Kamboj, S., Rana, S., \& Drave, V. A. (2020). Factors Driving Consumer Engagement and Intentions with Gamification of Mobile Apps. Journal of Electronic Commerce in Organizations, 18(2), 17-35. doi:10.4018/ JECO.2020040102

Khan, S. (2021). Consumer E-Loyalty for E-Grocery Shopping in a Metro City of India: Role of Flow and TAM Antecedents. In Research Anthology on E-Commerce Adoption, Models, and Applications for Modern Business (p. 21). IGI Global. doi:10.4018/978-1-7998-8957-1.ch082

Khanna, P., \& Sampat, B. (2015). Factors Influencing Online Shopping During Diwali Festival 2014: Case Study of Flipkart and Amazon. Journal of International Technology \& Information Management, 24(2), 65-86. http:// scholarworks.lib.csusb.edu/jitimAvailableat: http://scholarworks.lib. csusb.edu/jitim/vol24/iss2/5\%0A http:// widgets.ebscohost. com/prod/customlink/hanapi/hanapi.php?profile=4dfs1 q6ik\%2BHE5p Tp1ZLu0eGT1tTR2 8jqzaLXyajL 2dTV482lyNz ZoJ mu5NS8q\%2Bnp kKU\%3D\&Des

Kim, H. Y., Lee, J. Y., Mun, J. M., \& Johnson, K. K. P. (2017). Consumer adoption of smart in-store technology: Assessing the predictive value of attitude versus beliefs in the technology acceptance model. International Journal of Fashion Design, Technology and Education, 10(1), 26-36. doi:10.1080/17543266.2016.1177737

Kňažková, V., \& Ondrušová, L. (2019). Virtual Currency and Its Importance in Today’s Digitized Society. Advance online publication. doi:10.46541/978-86-7233-380-0_50

Kock, N. (2011). Using WarpPLS in e-collaboration studies: Descriptive statistics, settings, and key analysis results. International Journal of e-Collaboration, 7(2), 1-18. doi:10.4018/jec.2011040101

Lin, H. F. (2007). The role of online and offline features in sustaining virtual communities: An empirical study. Internet Research, 17(2), 119-138. doi:10.1108/10662240710736997

Loch, K. D., Straub, D. W., \& Kamel, S. (2003). Diffusing the internet in the Arab world: The role of social norms and technological culturation. Global Information Systems: The Implications of Culture for IS Management, 50(1), 143-177. doi:10.1109/TEM.2002.808257

López-Bonilla, L. M., \& López-Bonilla, J. M. (2017). Explaining the discrepancy in the mediating role of attitude in the TAM. British Journal of Educational Technology, 48(4), 940-949. doi:10.1111/bjet.12465

McLean, G., \& Wilson, A. (2016). Evolving the online customer experience ... is there a role for online customer support? Computers in Human Behavior, 60, 602-610. doi:10.1016/j.chb.2016.02.084

Mohammad Usman, Q. (2020). Virtual currency: A need for its regulation. ILI Law Review, 129-143.

Moin, M. T., \& Rahman, M. A. U. (2019). Eliminating laundering of virtual currency. Academic Press.

Prashar, S., Sai Vijay, T., \& Parsad, C. (2015). Antecedents to online shopping: Factors influencing the selection of web portal. International Journal of E-Business Research, 11(1), 35-55. doi:10.4018/ijebr.2015010103 
Raj, B., \& Gupta, D. (2018). Factors Influencing Consumer Responses to Marketing Gamification. 2018 International Conference on Advances in Computing, Communications and Informatics, ICACCI 2018, 15381542. doi:10.1109/ICACCI.2018.8554922

Rajan, T. (2020). The Flipkart Story in India: From the Start to Walmart. Asian Journal of Management Cases. $10.1177 / 0972820120914526$

Raman, P. (2020). Examining the importance of gamification, social interaction and perceived enjoyment among young female online buyers in India. Young Consumers. Advance online publication. doi:10.1108/YC05-2020-1148

Rapp, A., Hopfgartner, F., Hamari, J., Linehan, C., \& Cena, F. (2019). Strengthening gamification studies: Current trends and future opportunities of gamification research. International Journal of Human Computer Studies, 127(November), 1-6. 10.1016/j.ijhcs.2018.11.007

Reinartz, W., Haenlein, M., \& Henseler, J. (2009). An empirical comparison of the efficacy of covariance-based and variance-based SEM. International Journal of Research in Marketing, 26(4), 332-344. doi:10.1016/j. ijresmar.2009.08.001

Sackheim, M. S., \& Howell, N. A. (2018). Virtual Currency Regulation Review. Law Business Research Ltd.

Sarstedt, M., Ringle, C. M., Smith, D., Reams, R., \& Hair, J. F. Jr. (2014). Partial least squares structural equation modeling (PLS-SEM): A useful tool for family business researchers. Journal of Family Business Strategy, 5(1), 105-115. doi:10.1016/j.jfbs.2014.01.002

Shin, D. H. (2008). Understanding purchasing behaviors in a virtual economy: Consumer behavior involving virtual currency in Web 2.0 communities. Interacting with Computers, 20(4-5), 433-446. doi:10.1016/j. intcom.2008.04.001

Teo, T. (2009). Is there an attitude problem? Reconsidering the role of attitude in the TAM: Colloquium. British Journal of Educational Technology, 40(6), 1139-1141. doi:10.1111/j.1467-8535.2008.00913.x

Tobbin, P. (2014). Investigating the Role of Attitude in the Adoption of Mobile Data Services. International Journal of E-Services and Mobile Applications, 6(1), 23-43. doi:10.4018/ijesma.2014010102

Tony, C. K. H., Chen, S. H., \& Lee, Y. W. (2020). Investigating the adoption intention of gamification apps on mobile services. International Journal of Mobile Communications, 18(3), 273. doi:10.1504/IJMC.2020.107105

Trauboth, M. (2020). Platform Business Models of Online Marketplaces-Similarities and Differences of Leading Platforms. Advance online publication. doi:10.13140/RG.2.2.10538.44489

Van Der Heijden, H. (2004). Van der Heijden/Hedonic Information Systems v iiicir c i Iv research n?te User Acceptance of Hedonic information systems. Management Information Systems Quarterly, 28(4), 695-704. doi: $10.2307 / 25148660$

Venkatesh, V. (2000). Determinants of perceived ease of use : Integrating control, intrinsic motivation, acceptance model. Inorganic Chemistry Communications, 11(3), 319-340.

Wang, Y., \& Mainwaring, S. D. (2008). Human-currency interaction": Learning from virtual currency use in China. Conference on Human Factors in Computing Systems - Proceedings, 25-28. doi:10.1145/1357054.1357059

Wong, D., Liu, H., Meng-Lewis, Y., Sun, Y., \& Zhang, Y. (2021). Gamified money: exploring the effectiveness of gamification in mobile payment adoption among the silver generation in China. Information Technology and People. doi:10.1108/ITP-09-2019-0456

Xi, N., \& Hamari, J. (2020). Does gamification affect brand engagement and equity? A study in online brand communities. Journal of Business Research, 109(January), 449-460. 10.1016/j.jbusres.2019.11.058

Yang, Y., Asaad, Y., \& Dwivedi, Y. (2017). Examining the impact of gamification on intention of engagement and brand attitude in the marketing context. Computers in Human Behavior, 73, 459-469. doi:10.1016/j. chb.2017.03.066 


\title{
APPENDIX: ITEMS PRESENT IN THE QUESTIONNAIRE
}

\author{
Perceived Usefulness - PU (Davis, 1989)
}

PU1: SuperCoins tend to be very useful in my Flipkart transactions.

PU2: I believe SuperCoins will help me improve my Flipkart transactions.

PU3: In my view, SuperCoins would help to increase the quality of Flipkart transactions.

Perceived Ease of Use - PEOU (Venkatesh, 2000)

PEOU1: I have realized that the provision to be straightforward and understandable.

PEOU2: I have realized that the provision does not necessitate a great deal of psychological exertion.

PEOU3: I have realized that the provision to be easy to use.

Attitude - AT (Van Der Heijden, 2004)

AT1: I'd be interested in purchasing a product from this website.

AT2: The idea of purchasing anything from this website appeals to me.

AT3: Purchasing a product from this website is a smart idea.

Intention to Use - IU (Davis, 1989)

IU1: In the future, I hope to transact with SuperCoins.

IU2: As much as possible, I want to use SuperCoins.

IU3: I recommend that others use SuperCoins.

IU4: In the forthcoming, I want to endure using SuperCoins.

Anoop George is a research scholar at the Cochin University of Science and Technology, School of Management Studies in Cochin, India. He received his MBA Marketing degree from Amrita Business School, India. His formal education includes a Bachelor of Business Administration specialized in Jewelry Design and Management. He has work experience from reputable retail corporate such as Tata Group, Shoppers Stop, etc., and has academic experience. His field of research includes gamification, loyalty, marketing, and game mechanics in modern business management.

Manu Melwin Joy is an assistant professor at the Cochin University of Science and Technology, School of Management Studies in Cochin, India. He has a Ph.D. degree and six Master's degrees from various verticals such as business administration, psychology, psychotherapy and counseling, sociology, to name a few. He has worked at various reputed organizations as a corporate trainer. From the perspective of gamification, consumer behavior, and customer loyalty, he has authored several seminal empirical, theoretical, and meta-analytical scholarly articles on several topics.

Muhammed Sajid is a research scholar at the School of Management Studies, CUSAT in Cochin, India. He is an MBA graduate from the University of Kerala. Formal education includes a Bachelor of Commerce and PG diploma in marketing management. His research interests include Gamification and Green Marketing.

Muhammed Nowfal S. is presently pursuing his Doctoral degree at the School of Management Studies, Cochin University of Science and Technology, Kochi, Kerala, India. He has four years of teaching experience in reputed management institutes. His research interests include Gamification, Marketing, Financial Management, Behavioral and Personal Finance, Human resources, and organizational psychology. 